\title{
Latihan beban dan plyometric: apakah mempengaruhi flying shoot atlet bola tangan?
}

\section{Weight training and plyometrics: do they affect the flying shoot of handball athletes?}

\section{Putri Cicilia Kristina ${ }^{* 1}$, Endie Riyoko1, Zihan Novita Sari ${ }^{2}$}

${ }^{1}$ Program Studi Pendidikan Jasmani, Universitas PGRI Palembang, Palembang, Indonesia

${ }^{2}$ Program Studi Pendidikan Jasmani, Kesehatan, dan Rekreasi, Universitas Negeri Malang, Malang, Indonesia

${ }^{*}$ Corresponding Author

\begin{abstract}
Abstrak
Penelitian ini bertujuan untuk mengetahui: (1) perbedaan antara latihan beban dan latihan plyometric pada atlet bola tangan; (2) latihan mana yang lebih baik bagi atlet yang memiliki kemampuan motorik tinggi yang dilatih dengan latihan beban atau latihan plyometric terhadap hasil flying shoot; (3) latihan mana yang lebih baik bagi atlet yang memiliki kemampuan motorik rendah yang dilatih dengan latihan beban atau latihan plyometric terhadap hasil flying shoot; dan (4) ada tidaknya interaksi antara metode latihan dan kemampuan motorik terhadap hasil flying shoot. Penelitian ini merupakan penelitian eksperimen dengan rancangan faktorial $2 \times 2$. Subjek dalam penelitian ini berjumlah 20 orang atlet di klub bola tangan SMAN 14 Palembang. Teknik analisis data yang digunakan adalah ANOVA dua jalur dengan taraf signifikansi 5\%. Hasil penelitian menunjukkan bahwa: (1) terdapat perbedaan yang signifikan antara latihan beban dan latihan plyometric terhadap kemampuan flying shoot; (2) hasil flying shoot bagi atlet yang memiliki kemampuan motorik tinggi yang dilatih dengan latihan beban lebih rendah dari rata-rata kelompok yang dilatih dengan latihan plyometric; (3) hasil flying shoot bagi atlet yang memiliki kemampuan motorik rendah yang dilatih dengan latihan beban lebih rendah dari rata-rata kelompok yang dilatih dengan latihan plyometric; dan (4) terdapat interaksi yang signifikan antara latihan beban dan latihan plyometrik terhadap kemampuan flying shoot.
\end{abstract}

Kata Kunci: Latihan Beban; Plyometric; Flying Shoot; Bola Tangan.

This study aims to determine: (1) the difference between weight training and plyometric training in handball athletes; (2) which exercise is better for athletes who have high motor skills who are trained with weight training or plyometric exercises on the results of flying shoots; (3) which exercise is better for athletes who have low motor skills who are trained with weight training or plyometric exercises on the results of flying shoots; and (4) whether or not there is an interaction between the training method and motor skills on the results of the flying shoot. This research is an experimental study with a $2 \times 2$ factorial design. The subjects in this study were 20 athletes at the handball club at SMAN 14 Palembang. The data analysis technique used was two-way ANOVA with a significance level of $5 \%$. The results showed that: (1) there was a significant difference between weight training and plyometric training on the ability to flying shoot; (2) the results of flying shoots for athletes who have high motor skills who are trained with weight training are lower than the average group trained with plyometric exercises; (3) the results of flying 
shoots for athletes who have low motor skills who are trained with weight training are lower than the average group trained with plyometric exercises; and (4) there is a significant interaction between weight training and plyometric training on flying shoot ability.

Keywords: Weight Training; Plyometrics; Flying Shoot; Handball.

Received: 25 Januari 2022; Revised: 28 Januari 2022; Accepted: 29 Januari 2022

Corresponding author: Putri Cicilia Kristina, Jln. PDAM Tirta Musi, Bukit Lama, Palembang, Sumatera Selatan

Email: putrick@univpgri-palembang.ac.id

\section{PENDAHULUAN}

Bola tangan merupakan olahraga yang sangat menarik untuk dimainkan oleh semua orang, baik pria maupun wanita. Permainan bola tangan pada prinsipnya diciptakan untuk menggerakkan dan melakukan aktivitas fisik sehingga terjadi pembakaran dalam tubuh dan meningkatkan performa atlet di lapangan, untuk mendapatkan performa yang optimal diperlukan latihan yang tepat bagi atlet yang akan digunakan untuk meningkatkan performa atlet. Pada dasarnya permainan bola tangan terdiri dari beberapa teknik dasar seperti (1) teknik menggiring bola, yaitu upaya pemain untuk mendekatkan bola ke daerah pertahanan lawan dengan cara memantulkan bola ke lantai, (2) teknik lempar, yaitu upaya memberikan bola kepada lawan. teman dengan menggunakan satu atau dua tangan, (3) teknik menangkap yaitu menerima lemparan dari teman, (4) teknik menembak ke gawang, yaitu menyerang agar menghasilkan poin (Susanto, 2017). Latihan merupakan proses perubahan ke arah yang lebih baik, yaitu meningkatkan kualitas fisik kemampuan fungsional peralatan tubuh dan kualitas psikologis anak untuk melatih (Mylsidayu, 2015). Tujuan dari latihan tersebut adalah untuk meningkatkan kemampuan pemain dengan meningkatkan prinsip beban latihan progresif sehingga dengan latihan yang terstruktur kemampuan pemain akan semakin meningkat. Setiap cabang olahraga memiliki ciri khas dan kebutuhan latihannya masing-masing oleh karena itu pelatih harus pintar-pintar dalam merancang program latihan agar tujuan latihan tercapai. Latihan adalah jenis aktivitas fisik yang memerlukan perencanaan, terstruktur, dan dilakukan secara berulangulang dengan maksud untuk meningkatkan atau mempertahankan satu atau lebih komponen kebugaran jasmani (Nasrulloh et al., 2018) dan metode 
latihan plyometric merupakan suatu bentuk latihan dengan tujuan agar otot mampu mencapai kekuatan yang maksimal dalam waktu yang sesingkatsingkatnya (Irfan et al., 2020). Fungsi latihan plyometric dapat dinyatakan bahwa peningkatan kemampuan daya sangat penting dan diperlukan untuk beberapa pencapaian prestasi olahraga. Untuk dapat menghasilkan atlet yang baik diperlukan suatu tes dasar yaitu keterampilan motorik karena setiap atlet memiliki kemampuan motorik yang berbeda-beda. Secara luas dan jelas bahwa kemampuan motorik adalah kemampuan umum yang berkaitan dengan pelaksanaan berbagai keterampilan atau tugas gerak. Keterampilan motorik adalah kemampuan untuk melakukan serangkaian gerakan fisik dalam urutan tertentu (Ulfah et al., 2021). Tujuan dari penelitian ini adalah untuk mengetahui: (1) perbedaan antara latihan beban dan latihan plyometric pada atlet bola tangan; (2) latihan mana yang lebih baik bagi atlet yang memiliki kemampuan motorik tinggi yang dilatih dengan latihan beban atau latihan plyometric terhadap hasil flying shoot; (3) latihan mana yang lebih baik bagi atlet yang memiliki kemampuan motorik rendah yang dilatih dengan latihan beban atau latihan plyometric terhadap hasil flying shoot; dan (4) ada tidaknya interaksi antara metode latihan dan kemampuan motorik terhadap hasil flying shoot.

\section{METODE}

Metode penelitian merupakan dasar dalam penelitian yang sangat penting, karena berhasil tidaknya dan kualitas hasil penelitian sangat ditentukan oleh ketepatan peneliti dalam menentukan metode penelitian (Maksum, 2018). Metode yang digunakan adalah metode penelitian eksperimen, dengan menggunakan rancangan eksperimen faktorial $2 \times 2$. Eksperimen faktorial adalah eksperimen di mana hampir semua level faktor digabungkan atau disilangkan dengan menggunakan semua level faktor satu sama lain dalam eksperimen (Fraenkel et al., 2012). Rancangan penelitian yang akan digunakan dalam penelitian ini menggunakan eksperimen faktorial $2 \times 2$. 
Tabel 1. Desain penelitian

\begin{tabular}{lll}
\hline \multicolumn{1}{c}{ Kemampuan Motorik (B) } & \multicolumn{2}{c}{ Latihan (A) } \\
& Latihan Beban (1) & \multicolumn{1}{c}{ Plyometrics (2) } \\
\hline Kemampuan Motorik Tinggi $\left(B_{1}\right)$ & $A_{1} B_{1}>$ & $A_{2} B_{1}$ \\
Kemampuan Motorik Rendah $\left(B_{2}\right)$ & $A_{1} B_{2}<$ & $A_{2} B_{2}$ \\
\hline
\end{tabular}

Semua data tingkat keterampilan motorik yang dibutuhkan dengan menggunakan IOWA Brace Test from (Boržikova, I., \& Belej, 2003). Sedangkan data flying shoot menggunakan permainan bola tangan dikumpulkan dengan pengujian. Sebelum melaksanakan tes keterampilan perlu dicari reliabilitas tes untuk tes flying shoot dan tes kemampuan motorik. Dengan menggunakan teknik ANOVA dua arah, peneliti dapat membandingkan beberapa rata-rata yang diturunkan dari beberapa kategori atau kelompok untuk perlakuan. Analisis data adalah suatu cara yang dilakukan untuk memperoleh atau menganalisis data yang diperoleh. Analisis data bertujuan untuk menguji kebenaran hipotesis yang telah dirumuskan. Teknik analisis data yang digunakan dalam penelitian ini adalah analisis varians dengan rancangan eksperimen faktorial $2 \times 2$ dan menggunakan uji lanjut Tukey dengan taraf signifikansi $=0,05$.

\section{HASIL}

Berdasarkan data yang diuraikan dalam penelitian ini terdapat dua kelompok yaitu kelompok latihan beban dan kelompok plyometric, dalam dua kelompok dibagi menjadi dua yaitu kemampuan motorik tinggi dan kemampuan motorik rendah melalui tes rangkaian tes kemampuan motorik.

Tabel 2. Data hasil penelitian

\begin{tabular}{cccc}
\hline \multirow{2}{*}{ Kemampuan Motorik } & \multicolumn{2}{c}{ Latihan } \\
\cline { 2 - 4 } & & $\begin{array}{c}\text { Latihan } \\
\text { Beban }\end{array}$ & $\begin{array}{c}\text { Latihan } \\
\text { Plyometric }\end{array}$ \\
\hline \multirow{3}{*}{ Tinggi } & $N$ & 5 & 5 \\
\cline { 2 - 4 } & St. Deviasi & 0,7 & 1,14 \\
\cline { 2 - 4 } Rendah & Mean & 9 & 11,4 \\
\cline { 2 - 4 } & St. Deviasi & 5 & 5 \\
\cline { 2 - 4 } & Mean & 7,83 & 0,55 \\
\hline \multirow{3}{*}{ Total } & $N$ & 10 & 8,6 \\
\cline { 2 - 4 } & St. Deviasi & 1,2 & 10 \\
\cline { 2 - 4 } & Mean & 8,1 & 1,7 \\
\hline
\end{tabular}


Pada tabel 3 dan tabel 4 merupakan hasil uji normalitas dengan menggunakan Uji Liliefors dan uji homogenitas dengan menggunakan Uji Bartlett.

Tabel 3. Hasil uji normalitas

\begin{tabular}{ccccc}
\hline Kelompok & $\mathbf{N}$ & $\mathbf{L}_{\text {count }}$ & $\mathbf{L}_{\text {tabel }}$ & Keterangan \\
\hline 1 & 10 & 0,13 & 0,25 & Normal \\
2 & 10 & 0,22 & 0,25 & Normal \\
3 & 5 & 0,30 & 0,33 & Normal \\
4 & 5 & 0,19 & 0,33 & Normal \\
5 & 5 & 0,24 & 0,33 & Normal \\
6 & 5 & 0,26 & 0,33 & Normal \\
\hline
\end{tabular}

Tabel 4. Hasil uji homogenitas

\begin{tabular}{cccccc}
\hline Kelompok & Variant & $\begin{array}{c}\text { Variant } \\
\text { Combined }\end{array}$ & $\mathbf{X}^{\mathbf{2}} \mathbf{h}$ & $\mathbf{X}^{2} \mathbf{t}$ & Keterangan \\
\hline 1 & 0,84 & & & & \\
2 & 0,92 & 0,89 & 0,06 & 7,81 & Homogen \\
3 & 1,07 & & & & \\
4 & 0,74 & & & \\
\hline
\end{tabular}

Berdasarkan tabel 3 dan tabel 4, data penelitian termasuk data yang normal dan homogen, sehingga pengujian hipotesis dapat dilanjutkan dengan menggunakan analisis varians. Setelah dilakukan uji normalitas dan uji homogenitas diketahui bahwa keempat kelompok sampel berdistribusi normal dan memiliki varians yang homogen. Kemudian dapat dilanjutkan dengan pengujian hipotesis menggunakan teknik two way ANOVA. Jika $F_{\text {hitung }}>F_{\text {tabel }}$ maka Ho ditolak dan Ha diterima Jika $F_{\text {hitung }}<F_{\text {tabel. }}$.

Tabel 5. Hasil ANOVA

\begin{tabular}{cccccc}
\hline Source of Variation & Dk & RJK & KT & F $_{\text {hitung }}$ & $\mathbf{F}_{\text {table }}$ \\
\hline 1 & 10 & 0,13 & 0,25 & & \\
2 & 10 & 0,22 & 0,25 & & \\
3 & 5 & 0,30 & 0,33 & 23 & 3,24 \\
4 & 5 & 0,19 & 0,33 & & \\
5 & 5 & 0,24 & 0,33 & & \\
6 & 5 & 0,26 & 0,33 & & \\
\hline
\end{tabular}

Dari daftar distribusi $\mathrm{F}$ dengan $d k$ pada pembilang 3 dan $d k$ pada penyebut 16 dan probabilitas 0,95 diperoleh $F_{\text {tabel }}=3,24$. Ternyata $F_{\text {hitung }}=$ $23>\mathrm{F}_{\text {tabel }}=3,24$, maka $\mathrm{H}_{\mathrm{o}}$ ditolak, dan dapat disimpulkan bahwa keempat jenis latihan tersebut berpengaruh berbeda nyata terhadap hasil flying shoot. Dengan kata lain, terdapat perbedaan pengaruh latihan beban dan latihan plyometric terhadap hasil flying shoot. 
Tabel 6. Hasil analisis perbandingan antara kelompok metode latihan beban dan metode latihan plyometric secara keseluruhan

\begin{tabular}{cccc}
\hline Compared group & Qvalue & Qtable & Keterangan \\
\hline A1 dengan A2 & 146,3 & 2,33 & Signifikan \\
\hline
\end{tabular}

Tabel 6 menunjukkan bahwa hasil perhitungan analisis varians $F_{\text {hitung }}$ antar kolom $(\mathrm{FA})=146,3<\mathrm{F}_{\text {tabel }}=2,33$, sehingga secara keseluruhan terdapat perbedaan antara metode latihan beban dan metode latihan plyometric terhadap kemampuan flying shoot. Sedangkan tabel 7 menunjukkan bahwa Hasil perhitungan interaksi $F_{\text {hitung }}(\mathrm{FAB})=4$ dan $\mathrm{F}_{\text {tabel }}$ $=2,33$ menunjukkan bahwa, $F_{\text {hitung }}>$ dari $F_{\text {tabel }}$, artinya terdapat interaksi antara metode latihan dan keterampilan motorik terhadap kemampuan flying shoot.

Tabel 7. Rangkuman hasil perhitungan analisis lanjutan dengan Uji Tukey

\begin{tabular}{cccc}
\hline Compared group & Qvalue & Qtable & Keterangan \\
\hline A1 dengan A2 & 4 & 2,33 & Signifikan \\
A1B1 dengan A2B1 & 4 & 1,86 & Signifikan \\
A1B2 dengan A2B2 & 2,77 & 1,86 & Signifikan \\
\hline
\end{tabular}

\section{PEMBAHASAN}

Hasil penelitian menunjukkan bahwa terdapat perbedaan yang signifikan dalam kemampuan flying shoot antara atlet yang dilatih dengan metode latihan beban dan metode latihan plyometric untuk atlet yang memiliki motorik tinggi maupun rendah. Hasil penelitian tersebut juga sejalan dengan penelitian dari (Al Ikhsan et al., 2021; Bal et al., 2011; Slimani et al., 2016) yang menyebutkan bahwa latihan plyometric dapat memberikan efek positif terhadap peningkatan performa fisik atlet.

Dalam latihan plyometric pada dasarnya fokus pada pengaktifan siklus peregangan dan pemendekan (stretch-shorthening cycle) secara cepat untuk menghasilkan power yang maksimal. Secara fungsinya otot ditarik sebelum kontraksi konsentris maksimal, lalu diikuti gerakan cepat dari fase eksentrik ke konsentrik yang membantu menstimulasi propioseptor untuk memfasilitasi peningkatan muscle recruitment dalam waktu yang minimal (Utamayasa et al., 2020).

Plyometric mempunyai keuntungan, memanfaatkan gaya dan kecepatan yang dicapai dengan percepatan berat badan melawan gravitasi, hal ini 
menyebabkan gaya dan kecepatan dalam latihan plyometric merangsang berbagai aktivitas olahraga seperti melompat, berlari dan melempar lebih sering dibanding dengan latihan beban atau dapat dikatakan lebih dinamis atau eksplosif.

Sedangkan latihan beban weight training adalah Latihan yang sistematis dengan menggunakan beban sebagai alat untuk menambah kekuatan otot guna mencapai tujuan, seperti memperbaiki kondisi fisik atlet, mencegah terjadinya cedera atau untuk tujuan kesehatan. Tujuan utama latihan beban adalah memperbaiki keseluruhan level dari kekuatan dan kebugaran (Juntara, 2019). Pelaksanaan latihan beban harus dilakukan secara teratur dan terukur serta harus diimbangi dengan pengaturan pola makan yang baik, istirahat cukup dan manajemen stres yang bagus. Frekuensi latihan hendaknya dilakukan 3-5 kali dalam seminggu dengan intensitas latihan tergantung pada tujuan latihan. Pengaturan pola makan dan asupan nutrisi juga harus diperhatikan.

Latihan beban adalah jenis olahraga umum untuk mengembangkan kekuatan yang menggunakan gaya berat gravitasi, untuk menentang gaya yang dihasilkan oleh otot melalui kontraksi konsentris atau eksentrik (Nasrulloh \& Shodiq, 2020). Bentuk Latihan tersebut di mana otot-otot tubuh mengalami kontraksi menggunakan berat badan atau perangkat lain untuk merangsang pertumbuhan/kerja otot, kekuatan dan daya tahan, dengan menargetkan kelompok otot dan jenis gerakan tertentu.

\section{KESIMPULAN}

Berdasarkan analisis hasil penelitian dan pembahasan di atas maka dapat disimpulkan bahwa terdapat perbedaan yang signifikan antara pengaruh metode latihan beban dengan latihan pylometric terhadap hasil flying shoot pada atlet bola tangan di SMA 14 Palembang.

\section{KONTRIBUSI PENULIS}

Penulis 1: Writing - Review \& Editing - Original Draft; Penulis 2: Methodology; Penulis 3: Software and Writing - Validating. 


\section{DAFTAR PUSTAKA}

Al Ikhsan, A. I., Giartama, G., \& Bayu, W. I. (2021). Latihan barrier hops untuk meningkatkan kemampuan tendangan lurus depan pencak silat. Bravo's : Jurnal Program Studi Pendidikan Jasmani Dan Kesehatan, 9(2), 56. https: / / doi.org/ 10.32682/bravos.v9i2.1886

Bal, B. S., Kaur, P. J., \& Singh, D. (2011). Effects of a short term plyometric training program of agility in young basketball players. Brazilian Journal of Biomotricity, 5(2), 106-116.

Boržikova, I., \& Belej, M. (2003). Application of Rasch Model Calibration of Iowa-Brace Test. Antropomotoryka, 25(25), 53-60.

Fraenkel, J. R., Wallen, N. E., \& Hyun, H. (2012). How to Design and Evaluate Research in Education. McGraw-Hill Education.

Irfan, M., Yenes, R., Irawan, R., \& Oktavianus, I. (2020). Kemampuan teknik dasar sepakbola. Jurnal Patriot, 2(3), 720-731. https://doi.org/ 10.24036/PATRIOT.V2I3.664

Juntara, P. E. (2019). Latihan kekuatan dengan beban bebas metode circuit training dan plyometric. Altius: Jurnal Ilmu Olahraga Dan Kesehatan, 8(2). https://doi.org/10.36706/altius.v8i2.8705

Maksum, A. (2018). Metodologi Penelitian dalam Olahraga. Unesa University Press.

Mylsidayu, A. (2015). Pembinaan Prestasi Olahraga. Citra Publishing.

Nasrulloh, A., Prasetyo, Y., \& Apriyanto, K. D. (2018). Dasar-dasar Latihan Beban. UNY Press, 1-140.

Nasrulloh, A., \& Shodiq, B. (2020). Pengaruh latihan beban dengan metode super set kombinasi diet OCD terhadap berat badan, presentase lemak dan kekuatan otot. JORPRES (Jurnal Olahraga Prestasi), 16(2), 54-65. https:/ / doi.org/ 10.21831/jorpres.v16i2.31613

Slimani, M., Chamari, K., Miarka, B., Del Vecchio, F. B., \& Chéour, F. (2016). Effects of Plyometric Training on Physical Fitness in Team Sport Athletes: A Systematic Review. In Journal of Human Kinetics (Vol. 53, Issue 1, pp. 231-247). Polish Academy of Science, Committee of Physical Culture. https://doi.org/10.1515/hukin-2016-0026

Susanto, E. (2017). Pengembangan tes keterampilan dasar olahraga bola tangan bagi mahasiswa. Jurnal Penelitian Dan Evaluasi Pendidikan, 21(1), 116-125. https://doi.org/10.21831/pep.v21i1.15784

Ulfah, A. A., Dimyati, D., \& Putra, A. J. A. (2021). Analisis Penerapan Senam Irama dalam Meningkatkan Kemampuan Motorik Kasar Anak Usia Dini. Jurnal Obsesi: Jurnal Pendidikan Anak Usia Dini, 5(2), 1844-1852. https://doi.org/10.31004/obsesi.v5i2.993

Utamayasa, I. G. D., Setijono, H., \& Wiriawan, O. (2020). The effect of plyometric exercise towards agility, speed, strength and explosive power of leg muscle. Sport $i$ Turystyka, 3(3), 81-88. https://doi.org/10.16926/sit.2020.03.22 